\title{
OTIOTOMICS
}

Revista de economía, empresa y sociedad

Dossier «Economía social y solidaria: experiencias y retos»

\section{La revolución de las finanzas éticas y solidarias}

\section{Joan Ramon Sanchis}

Catedrático de Organización de Empresas. Universitat de València.

RESUMEN La exclusión financiera, a la vez que produce mayor exclusión social y pobreza, está contribuyendo a la aparición de nuevas formas organizativas en finanzas, bancarias y no bancarias, basadas en la ética y la solidaridad, que favorecen la inclusión entre los colectivos más marginados. La banca ética y los bancos de proximidad, entre los que se incluyen las cooperativas de crédito, ofrecen una alternativa a la banca convencional y cada vez tienen mayor acogida. Por otra parte, la propia sociedad civil está liderando un movimiento que ha propuesto nuevas iniciativas de finanzas éticas y solidarias no bancarias, como las cooperativas de servicios financieros, las cooperativas integrales, las finanzas colaborativas, las comunidades autofinanciadas, los bancos de tiempo, las monedas sociales y los bancos comunitarios de desarrollo, entre otras. El presente trabajo analiza los principales aspectos derivados de estos procesos de cambio a nivel mundial y destaca los posibles riesgos que puede tener el uso de estos instrumentos de financiación por parte de las grandes corporaciones financieras y no financieras a través de las nuevas aplicaciones informáticas en las finanzas, o fintech. Las finanzas éticas y solidarias se han convertido en un instrumento apropiado para la inclusión, pero no dejan de existir ciertos riesgos que habrá que tener en cuenta.

PALABRAS CLAVE finanzas éticas; exclusión financiera; banca ética; banca cooperativa; fintech; finanzas colaborativas

\section{The revolution of ethical and solidarity finance}

\begin{abstract}
Financial exclusion, while producing greater social exclusion and poverty, is contributing to the emergence of new types of organization in finance, banking and non-banking. Based on ethics and solidarity, such organizations favour the inclusion of the most marginalized groups. Ethical banking and community banking (including credit unions) offer an alternative to conventional banking and are increasingly being accepted. Moreover, civil society itself is leading a movement through which new non-banking ethical and solidarity finance initiatives are also emerging. Examples include financial services cooperatives, integrated cooperatives, collaborative finance, self-financed communities, time banks, social currencies and community development banks, among others. This paper analyses the main aspects arising globally from these processes of change, and highlights potential risks where these initiatives are used by large financial and nonfinancial corporations through new finance technologies (FinTech). Ethical and solidarity finance
\end{abstract}


have become an appropriate instrument for inclusion, but certain risks remain that must be taken into account.

KEYWORDS ethical finance; financial exclusion; ethical banking; cooperative banking; FinTech; collaborative finance

\section{Introducción}

Con la actual crisis económica, las tasas de exclusión social y de pobreza se están disparando también en el mundo occidental, como consecuencia, en gran medida, del incremento de las desigualdades económicas, pero también debido al aumento de la exclusión financiera. Esta última está alcanzando niveles preocupantes por las medidas que los gobiernos europeos están tomando en relación con las reformas de sus sistemas financieros, al acometer estrictos procesos de concentración bancaria que se traducen en intensos procesos de reestructuración, que incluyen, entre otras medidas, el cierre de oficinas bancarias, sobre todo en aquellos municipios de menor dimensión que no son suficientemente rentables para los bancos. La obsesión por la rentabilidad y la eficiencia, como objetivos prioritarios de los bancos, junto a las medidas legales tomadas por las principales instituciones de la Unión Europea (Banco Central Europeo, Comisión Europea) respecto a los niveles de capitalización y de solvencia, está provocando un incremento de la exclusión financiera, que afecta especialmente a los colectivos con menores recursos y en situación de marginación (Sanchis, 2013).

En el año 2008, la Comisión Europea definió la exclusión financiera como «el proceso mediante el cual las personas se encuentran con dificultades en el acceso y/o uso de los servicios y productos financieros adecuados a sus necesidades y que les permita llevar una vida social normal en la sociedad a la que pertenecen». Según el tipo de sociedad en el que vivimos, carecer de productos y servicios financieros básicos, como disponer de una cuenta bancaria o poder realizar transferencias y hacer reintegros, tiene unas consecuencias u otras. España, por ejemplo, es un país muy «bancarizado", y resulta realmente complicado vivir sin disponer de una cuenta bancaria. Sin embargo, en el mundo hay millones de personas que viven sin bancos, por diferentes razones. Unos lo hacen por obligación, por su situación de marginalidad (inmigrantes ilegales y personas sin techo, por ejemplo), porque viven en municipios rurales pobres (donde no llegan los bancos) o porque no pueden acceder a los bancos por las restricciones y condiciones que estos les imponen (por las exigencias de rentabilidad de los bancos). Los motivos de la exclusión financiera son muy diversos (Comisión Europea, 2008). La exclusión financiera ha sido un hecho reconocido y ampliamente extendido en el mundo en desarrollo, pero después del estallido de la crisis de principios del siglo XXI, esta se ha extendido también al mundo occidental, en la medida en que los bancos convencionales han ido ampliando su poder de mercado debido a la concentración. La disminución en el número de entidades bancarias y sus procesos de racionalización y reestructuración ${ }^{1}$ están provocando un marcado aumento de la exclusión financiera, especialmente en las zonas rurales y en los municipios de menor población, lo que a su vez produce un incremento en la exclusión social. En la actualidad, la exclusión financiera se da no solamente cuando las personas no pueden acceder a productos y servicios financieros básicos, sino también cuando resulta muy complejo y difícil acceder al crédito, lo que se extiende no solo a las personas, sino también al emprendimiento, al trabajo autónomo y a las empresas de reducida dimensión (microempresas y pequeñas y medianas empresas) (Sanchis, 2015).

Frente al fenómeno de la exclusión financiera tenemos la otra cara de la moneda, la inclusión financiera. La OCDE la define como «el proceso de promoción del acceso asequible, oportuno y adecuado a un rango de productos y servicios financieros regulados y a la ampliación de su uso". La inclusión financiera se consigue a través de mecanismos que favorecen el acceso (como, por ejemplo, las infraestructuras financieras mediante

1. Eufemismos que se utilizan para referirse al aumento de la productividad y de la eficiencia bancaria mediante el cierre de oficinas y el despido de trabajadores. 
las tecnologías a través de Internet), facilitando el uso con la creación de productos y servicios financieros accesibles (frente a la complejidad derivada de la ingeniería financiera que crea productos como las participaciones preferentes, los warrant, las hipotecas multidivisa, etc.), mediante la mejora de la cultura y la educación financieras (conocimiento y uso responsable de los productos y servicios financieros) y garantizando la protección del consumidor financiero (AFI, 2013). La mayoría de estos elementos están fallando actualmente, y por eso se está incrementando la exclusión financiera. Pero existen bancos, como los bancos éticos y los cooperativos, además de otras formas de financiación no bancaria, que están contribuyendo a mejorar la inclusión financiera. Cuando las administraciones públicas dejan de cumplir con sus obligaciones con la ciudadanía y olvidan las medidas que favorecen el acceso a los productos y servicios financieros básicos, ha sido la propia sociedad civil la que se ha movilizado creando nuevos instrumentos que posibiliten la inclusión financiera.

Precisamente, el objetivo del presente trabajo es el de analizar las diferentes opciones financieras que están surgiendo desde los movimientos sociales como respuesta a las consecuencias de la crisis financiera y económica, y que tienen como finalidad favorecer la inclusión financiera para así mejorar la inclusión social y reducir la pobreza. Se analizarán tanto los bancos que desde una perspectiva más social y humana -bancos éticos y bancos cooperativos- se están consolidando como alternativa a la banca convencional, como todas aquellas otras iniciativas que, desde las microfinanzas, están surgiendo de la propia sociedad civil, aprovechando las nuevas tecnologías de la información y la comunicación. Para ello, el trabajo se ha estructurado en dos apartados, además de la introducción y las conclusiones finales. En el primer apartado se analiza el papel que desempeñan en la actualidad la banca ética y la banca cooperativa y las características que las unen y, a la vez, las diferencian de los bancos convencionales. En el segundo apartado se estudian las alternativas más conocidas dentro del mundo de las finanzas éticas y solidarias, englobadas dentro de lo que se denomina microfinanzas, así como las finanzas colaborativas y el papel de las fintech en el proceso de evolución de las finanzas éticas y solidarias.

\section{La banca ética y cooperativa como alternativa a la banca convencional}

La banca ética nace en Estados Unidos en los años sesenta del siglo xx como una herramienta al servicio de las personas excluidas del sistema financiero, con el fin de proporcionarles financiación para emprender proyectos o negocios de impacto social. Así, los primeros bancos éticos van dirigidos a grupos de personas marginados o en exclusión social, como las mujeres y las personas de raza negra. Posteriormente, los bancos éticos se van extendiendo, tanto geográfica como socialmente, y a finales de los sesenta y comienzos de los setenta empiezan a constituirse los primeros bancos éticos en Europa. Hoy en día, la banca ética es una realidad contrastada y consolidada y, lo más importante, ha demostrado que la banca puede ser viable manteniendo criterios éticos y sociales. No es necesario especular con el dinero de los clientes para ser rentable y se puede ser rentable desde el punto de vista financiero y social a la vez. Bajo este argumento, cualquier banco podría adoptar criterios éticos en su funcionamiento sin poner en peligro su viabilidad económica; conviene señalar, pues, que el objetivo debería ser que toda la banca fuera ética y no tener que diferenciar entre una banca que es ética y otra que no lo es.

Los bancos éticos se basan en los principios de la economía solidaria, que son los siguientes:

1. Igualdad: sistemas de retribución con pocas diferencias salariales.

2. Empleo: empleo estable y de calidad y acceso al empleo de los colectivos con mayor riesgo de exclusión.

3. Sostenibilidad: protección del medio ambiente y uso adecuado de los recursos naturales.

4. Cooperación: colaboración tanto dentro de la organización (entre las personas) como fuera (con otras organizaciones).

5. Responsabilidad social: compromiso con el entorno.

6. Ánimo de lucro limitado: reinvertir parte de los beneficios económicos en la sociedad. 
Mediante estos seis principios básicos, los bancos éticos establecen unos códigos de conducta que están basados en dos características principales: la transparencia y la inversión socialmente responsable. Son bancos que utilizan el dinero de los depositantes para invertir en proyectos sociales y medioambientales y en ningún caso financian actividades fraudulentas, ilegítimas o no éticas, como la fabricación de armamento, el blanqueo de dinero negro, la especulación o el abuso laboral. Además, todas sus inversiones son públicas, de manera que cualquier ciudadano puede acceder a dicha información y comprobar a qué están destinando su dinero este tipo de bancos.

En Europa existen dos modelos diferentes de banca ética: el modelo centroeuropeo, representado por Triodos Bank, y el modelo del sur de Europa, representado por Banca Popolare Ética. Ambos se basan en los seis principios y las dos características señalados anteriormente, y la diferencia está en la forma jurídica que adoptan cada uno de ellos: Triodos Bank es una sociedad anónima, mientras que la Banca Popolare Ética es una cooperativa de crédito. Esta diferente forma jurídica se traduce en que cuando un banco ético es a la vez una cooperativa de crédito, su modelo de gestión es un modelo democrático y participativo, en el que los clientes del banco pueden a la vez ser socios del mismo, participando directamente en sus decisiones. Esto nos lleva a introducir el concepto de banco cooperativo ${ }^{2}$ como un tipo de entidad distinta a la convencional, dado que aunque los bancos cooperativos no son bancos éticos por regla general (algunos de ellos sí lo son, como hemos comentado en el caso de la Banca Popolare Ética), sí son bancos sociales arraigados en el territorio y vinculados directamente a las necesidades de financiación de la economía real. En España, la banca ética no ha tenido ningún tipo de implantación, seguramente por la fuerte presencia de las cajas de ahorros y de las cooperativas de crédito, que de alguna manera, a través de su negocio de banca minorista y de su obra social, han cubierto el segmento de mercado que en otros países europeos cubría la banca ética. En la actualidad, en España operan los dos modelos de banca ética, el de Triodos Bank desde principios de la década del 2000 y el de la Banca Popolare Ética a través de Fiare Banca Ética desde el año 2014. Como se puede observar, son de muy reciente implantación, por lo que, aunque están teniendo un crecimiento espectacular, sobre todo desde el estallido de la crisis financiera, siguen teniendo una escasa visibilidad a causa del desconocimiento por parte de la sociedad.

La Unión Europea ha introducido recientemente el concepto de community banking, o banca de proximidad, como un tipo de bancos locales dedicados a financiar la economía productiva local, entre los cuales se encuentran las cajas de ahorros y las cooperativas de crédito o bancos cooperativos. Los bancos cooperativos surgieron en la segunda mitad del siglo xIx, en plena revolución industrial, para hacer frente a las necesidades de financiación de los artesanos (bancos profesionales y populares) y de los pequeños agricultores (cajas rurales). Se trata, por tanto, de bancos de más de cien años de antigüedad, de mayor implantación que los bancos éticos (Sanchis, 2013). Han estado muy unidos a las empresas locales, especialmente a las cooperativas y empresas de la economía social (Campos y Sanchis, 2014). Algunos de estos bancos cooperativos son bancos democráticos, en los que más del $90 \%$ de sus trabajadores son socios del banco, como es el caso de Laboral Kutxa y Caixa Popular (Campos y Sanchis, 2015). En Europa, los bancos cooperativos surgieron en Alemania y posteriormente se fueron extendiendo a lo largo del continente. En la actualidad, los bancos cooperativos representan una cuota de mercado de entre el $20 \%$ y el $30 \%$ en países como Alemania, Países Bajos, Austria o Francia. En España, la cuota de mercado es bastante menor (del 5-6\%), aunque tienen un peso cualitativo muy importante y han jugado un papel clave en la financiación del cooperativismo de trabajo asociado y del cooperativismo agrario. No obstante, en España las cooperativas de crédito están seriamente amenazadas por los procesos de fusiones bancarias y por la concentración del sector, por lo que de no haber un cambio político considerable, podrían desaparecer en un breve espacio de tiempo.

2. Esta es la denominación habitual que toman en Europa, aunque en España son más conocidos con la denominación de cooperativas de crédito y cajas rurales. 


\section{Alternativas financieras éticas y solidarias surgidas de la sociedad civil}

Además de los bancos éticos y cooperativos, durante estos años de crisis han proliferado toda una serie de iniciativas nacidas desde abajo hacia arriba, dirigidas a favorecer la inclusión financiera y contrarrestar los efectos negativos de la crisis financiera y económica, y de las medidas adoptadas por los gobiernos europeos. Todas estas alternativas tienen en común el hecho de que surgen de los movimientos sociales y de protesta nacidos al calor de la crisis. Tienen sus orígenes en los grupos de consumo y en el concepto de prosumidor o prosumer (productor y consumidor en una misma persona) y su finalidad es la de eliminar los intermediarios financieros (principalmente los bancos), creando canales directos o canales cortos para el acceso a la financiación (tanto para el consumo como para la inversión). Como veremos en el siguiente apartado, el uso de las redes sociales y de la tecnología también han sido clave en este proceso.

Es importante tener en cuenta la diferencia entre los diferentes instrumentos financieros que la sociedad civil ha implementado para facilitar la inclusión y los nuevos sistemas de intermediación financiera que también se están constituyendo fuera de la intervención y la supervisión pública, y que se incluyen bajo la denominación de banca en la sombra o Shadow banking. En el año 2011, el Consejo de Estabilidad Financiera definía la banca en la sombra como un «sistema de intermediación crediticia conformado por entidades y actividades que están fuera del sistema bancario tradicional». Se trata, por tanto, de actividades financieras que están fuera del control y la supervisión, sin garantía pública, lo que puede suponer un elevado riesgo. Porque, además, estas actividades, a diferencia de las derivadas de las iniciativas surgidas de la sociedad civil, se dedican a la especulación financiera a través de diferentes mecanismos, como son los fondos de inversión (monetarios, inmobiliarios, de cobertura, etc.).

Las alternativas financieras éticas y solidarias toman la forma de cooperativas (estructuras formales) o de grupos de personas que establecen relaciones de cariz cooperativista entre ellas (estructuras no formales). Entre las primeras destacan las cooperativas de servicios financieros (como Coop57 en España y Oikocredit en Países Bajos) y las cooperativas integrales. Ambos tipos ofrecen servicios financieros a sus socios, proporcionándoles la financiación necesaria en condiciones adecuadas. Las cooperativas integrales ofrecen servicios múltiples, no solo financieros. Entre las estructuras no formales se incluyen una gran diversidad de opciones, como las redes de trueque, las comunidades autofinanciadas, los fondos sociales rotatorios, los bancos de tiempo o las monedas sociales, entre otras. Todas ellas se caracterizan por evitar la especulación del dinero y por gestionarse con criterios, además de éticos y solidarios, participativos y autogestionarios. Los usuarios de los créditos son a la vez los ahorradores o depositantes de los fondos a través de los cuales se presta. La mayoría de estas iniciativas surgen en los países latinoamericanos en otras épocas de crisis, que han sido importadas y adaptadas al mundo occidental.

Todas estas iniciativas descritas se pueden englobar dentro de lo que se denomina las microfinanzas, que incluyen todo tipo de productos y servicios financieros (de ahorro, de inversión y de crédito) para personas en situación de pobreza, microempresas o clientes de bajos ingresos. El producto estrella de las microfinanzas son los microcréditos, que corresponden a préstamos o créditos de importes reducidos concedidos a personas en riesgo de exclusión y que no cuentan con garantías reales. Estos tienen su origen en el Graemeen Bank -banco de los pobres- de Bangladesh. Aunque las iniciativas apuntadas contribuyen a la inserción financiera y pueden ser instrumentos positivos, también tienen un lado oscuro que conviene no olvidar. Algunos grandes bancos se han dado cuenta de que algunas de estas iniciativas representan nichos de mercado con una elevada rentabilidad, por lo que están actuando también en estos ámbitos. Sin embargo, cuando son los bancos convencionales los que ofrecen este tipo de productos financieros, se desvirtúan y dejan de cumplir la función social para la que se crearon. Un ejemplo muy evidente es el de los microcréditos, donde están participando ya bancos de gran tamaño con un enorme éxito.

El uso de las redes sociales y de las TIC ha facilitado también el surgimiento de la denominada economía colaborativa, que afecta también a las finanzas. Crowlending y Crowdfunding son las formas de finanzas colaborativas más conocidas y obedecen a un planteamiento más extenso conocido como micromecenazgo. Se 
trata de compartir la financiación de un proyecto a través de las redes sociales y puede tomar diferentes formas: recompensa, donación, inversión y préstamos. La forma más habitual es la de la recompensa, que consiste en realizar una preventa o lo que es lo mismo, la aportación que se realiza al proyecto posteriormente es compensada con la entrega del producto o servicio que se ha financiado. En principio, las finanzas colaborativas suponen la eliminación de los intermediarios financieros, por lo que son también una manera de facilitar la inclusión financiera, sobre todo cuando se trata de financiar proyectos de carácter social. Sin embargo, una parte importante de estas está siendo controlada por grandes plataformas virtuales que dependen de grandes empresas, y es ahí donde aparece el riesgo, pues pueden convertirse en un negocio financiero más dominado por las grandes corporaciones.

El riesgo es aún mayor si nos referimos a las fintech, una propuesta de finanzas alternativas a través del uso de las tecnologías, como es el caso del bitcoin o las monedas electrónicas encriptadas y, en general, los diferentes medios de pago directos a través de las nuevas tecnologías. En la actualidad se está hablando mucho de la desaparición del dinero efectivo por el pago a través de los móviles y otras aplicaciones; de hecho, en algunos países como Dinamarca ya se ha puesto en práctica. La cuestión es si estas nuevas formas de operaciones financieras son positivas para los ciudadanos o si, por el contrario, nos pueden esclavizar aún más. Conviene tener presente que la desaparición del dinero en efectivo va a producir una mayor dependencia de las redes tecnológicas, y si estas redes están dominadas por grandes compañías, el resultado es claramente negativo para los ciudadanos. Se ha de pensar que los grandes bancos ya han descubierto este nicho de mercado y se están preparando para entrar a competir en él, bien directamente creando sus propios canales de pago o bien comprando las empresas, con lo que las finanzas colaborativas pueden acabar convirtiéndose en un área de negocio más de los grandes bancos especuladores.

\section{Conclusiones}

A lo largo del trabajo hemos visto que con la crisis financiera han ido surgiendo nuevas opciones de financiación alternativas a la banca convencional, controladas por la propia sociedad civil, cuyo propósito es favorecer la inclusión financiera, especialmente entre los colectivos más desprotegidos. Los bancos éticos y la banca cooperativa, por un lado, y las microfinanzas solidarias y el micromecenazgo, por otro, son opciones cada vez más valoradas por los ciudadanos. Sin embargo, el atractivo económico que suponen algunas de estas ideas para la iniciativa privada representa un riesgo elevado, pues pueden acabar en manos de la gran banca y de grandes grupos empresariales a través del control de las nuevas tecnologías de la información y la comunicación.

Para mantener el carácter social de las finanzas éticas y solidarias es fundamental que la sociedad civil siga controlando las estructuras organizativas que han creado, conservando los principios de igualdad, cooperación, sostenibilidad, responsabilidad social, participación asamblearia y autogestión.

\section{Referencias bibliográficas}

AFI (2013). «Putting financial inclusion on the global map». En: The 2013 Maya Declaration Progress Report. Bangkok: Alianza para la Inclusión Financiera - AFI.

CAMPOS CLIMENT, V.; SANCHIS PALACIO, J. R. (2014). El modelo Consum: una cooperativa responsable y sostenible. Valencia: Vincle Editorial.

CAMPOS CLIMENT, V.; SANCHIS PALACIO, J. R. (2015). Caixa Popular: un modelo de banca cooperativa social y diferente. Valencia: Vincle Editorial.

COMISIÓN EUROPEA (2008). Financial Services Provision and Prevention of Financial Exclusion. Bruxelles: Directorate-General for Employment, Social Affairs and Equal Opportunities Inclusion, Social Policy Aspects of Migration, Streamlining of Social Policies. 
SANCHIS PALACIO, J. R. (2013). La banca que necesitamos. De la crisis bancaria a la banca ética: una alternativa socialmente responsable. Valencia: Publicaciones de la Universidad de Valencia.

SANCHIS PALACIO, J. R. (2015). ¿Es posible un mundo sin bancos? La revolución de las finanzas éticas y solidarias. Barcelona: El Viejo Topo.

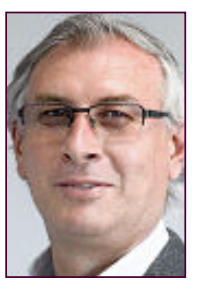

\section{Joan Ramon Sanchis} joan.r.sanchis@uv.es

\section{Catedrático de Organización de Empresas. Universitat de València}

Catedrático de la Universitat de València y doctor en Economía de la Empresa (Premio Extraordinario de Doctorado). Director del máster universitario en Economía Social (Cooperativas y Entidades no lucrativas) de la Universitat de València. Es autor de numerosos artículos científicos sobre economía social, cooperativismo y banca y de libros como ¿Es posible un mundo sin bancos? La revolución de las finanzas éticas y solidarias (2015) y La banca que necesitamos. De la crisis financiera a la banca ética: una alternativa socialmente responsable (2013), y coautor de obras como Caixa Popular: un modelo de banca cooperativa social y alternativa (2015) y El modelo Consum: una cooperativa responsable y sostenible (2014).

Los textos publicados en esta revista están sujetas -salvo que se indique el contrario- a una licencia de Reconocimiento 3.0 España de Creative Commons. Podéis copiarlos, distribuirlos, comunicarlos públicamente y hacer obras derivadas siempre que reconozcáis los créditos de las obras (autoría, nombre de la revista, institución editora) de la manera especificada por los autores o por la revista. La licencia completa se puede consultar en http://creativecommons.org/licenses/by/3.0/es/deed.ca.

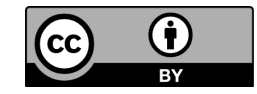

